\title{
Eurocurrículo II de Química Analítica
}

\author{
MAR I F I L M E A G. F, C. CAMÕE *
}

\begin{abstract}
"Analytical Chemists fall in two categories: specialists and generalists. Basic education aims at more general knowledge. Any specialization, in particular at universities with chairs in Analytical Chemistry demands extended education."

B.te Nijenhuis-Mikrochim. Acta (1991), II, 550-554
\end{abstract}

Na sequência de trabalho desenvolvido anteriormente, que levou à elaboração do EUROCURRículo I [1], a Divisão de Química Analítica da Federação das Sociedades de Química Europeias (DAC/FECS) acompanhou a sua implementação.

No contexto das actividades desenvolvidas com a ECTN (European Chemistry Thematic Network) no sentido da harmonização dos currículos de Química na Europa (processo de Bolonha), a DAC apresenta o resultado de reavaliação do panorama europeu do ensino actual de Química Analítica, propondo o EUROCURRÍ́CULO II.

Tal como no EUROCURRículo I, as actuais recomendações consideram dois níveis de ensino, básico e avançado. A componente básica é obrigatória para o nível de "Eurobacharel". A parte avançada é obrigatória para formação específica em Química Analítica.

Por razões históricas, a Química Analítica não tem ainda, em diversas universidades o estatuto de área de Química independente. As recomendações que se seguem apontam para cursos concisos e abrangentes sobre os fundamentos da Química Analítica contemporânea e centram-se em procedimentos, métodos e técnicas actuais da Química Analítica. Estudos de Casos, Resolução de Problemas Analíticos e Garantia da Qualidade são os princípios didácticos que prevalecem. O conteúdo dos cursos cobre, no essencial, tanto a análise quantitativa como a estrutural.

Todos os tópicos de Química, com orientação predominante para as substâncias, deverão ser tratados nos domínios correspondentes da Química (ex: Química Inorgânica, Química Orgânica, Bioquímica). A Química-Física tem por âmbito a fundamentação teórica da Química, enquanto o objectivo da Química Analítica é o de lidar com "amostras reais".

O desenvolvimento do EUROCURRÍCULO I foi fruto do trabalho do, na altura Grupo de Trabalho de Química Analítica/WPAC, actualmente DAC, publicado numa série de artigos [2-5], intitulada Educação e Formação em Química Analítica.

No documento saído da primeira discussão da ECTN, ainda sem a colaboração de Químicos Analistas, do total de 180 unidades de crédito, apenas 5 eram atribuídas à Química Analítica! Após inúmeros protestos de Químicos Analistas Europeus, representantes da DAC foram convidados a integrar a ECTN (Reiner Salzer- Universidade de Dres-
den-De, Coordenador do Grupo de Trabalho da DAC em Ensino da Química Analítica) e a componente obrigatória de Química Analítica subiu para 15 créditos. Tal não inclui nem o tempo para o desenvolvimento de Projecto Final de graduação, nem especialização; 15 créditos, representam $8,5 \%$ do total de créditos de leccionação para o Eurobacharel, o que é metade do que foi considerado no EUROCURRÍCULO I. É, portanto imprescindivel que a Química Geral e outras disciplinas forneçam conhecimentos e competências que libertem tempo para o ensino da Química Analítica. Não é de mais relembrar que um ensino baseado exclusivamente em métodos, ex: Cromatografia, Espectroscopia, Sensores, Quimiometria, poderia caber em qualquer currículo de Química, mas um currículo sustentável de Química Analítica requer orientação, enquadramento e exploração dos princípios analíticos fundamentais em situações da "vida real".

A conversão de 15 créditos em horas de leccionação ("horas de contacto") tem associados alguns pressupostos:

- A "carga de trabalho" por cada hora de Aula Teórica é 3, ou seja, o aluno necessita de 3 horas de pré- e póspreparação por hora de Aula Teórica,

- A "carga de trabalho" por cada hora de Aula de Laboratório é 2,

- A "carga de trabalho" por cada hora de Seminário é 1 , 


\section{EUROCURRICULO I}

1 - Tópicos Gerais

2 - Análise química

2.1 - Operações Unitárias*

2.2 - Métodos e Aplicações

3 - Análise Física

3.1 - Análise Elementar

3.2 - Análise de Compostos

3.3 - Análise de Superfícies * *

3.4 - Análise Estrutural

4 - Química Analítica I Baseada em

Computador

4.1 - Hardware e Software ${ }^{\star \star \star}$

4.2 - Interface entre Instrumen-

$\operatorname{tos}^{\star * *}$

Analíticos e Computadores

* Passar para Química Geral

* De uma forma geral, para além de formação

básica

** Não obrigatório
EUROCURRICULO II

\begin{tabular}{lcc} 
& \multicolumn{2}{c}{ Aulas Teóricas } \\
& Créditos & Horas \\
Introdução & 0,4 & 3 \\
Análise Química por via Húmida & 0,8 & 6 \\
Estatística, Quimiometria e & 1 & 8 \\
Controlo de Qualidade & &
\end{tabular}

Espectroscopia

$\begin{array}{lcc}\text { Atómica } & 1 & 8 \\ \text { Molecular } & 1,2 & 10 \\ \text { Estrutural } & 0,8 & 6\end{array}$

Separações

$\begin{array}{lcc}\text { MS } & 0,8 & 6 \\ \text { Cromatografia } & 1,2 & 10 \\ \text { Hifenação } & 0,4 & 4\end{array}$

Métodos

Electroanalíticos $\quad 0,4 \quad 4$

Radioanalíticos $\quad 0,2 \quad 2$

Térmicos $\quad 0,2 \quad 0$

Bioanalíticos $\quad 0,2 \quad 2$

Automação $\quad 0,4 \quad 4$

Total

9

75
- A razão entre o número de horas de Aulas Teóricas e Aulas de Laboratório deve ser 1:2,

- As recomendações básicas assentam em apenas Aulas Teóricas e Aulas de Laboratório. Os Seminários podem ser facilmente incorporados a expensas de Aulas Teóricas ou de Laboratório.

Isto tem como resultado:

- Ensino de Química Analítica ao nível de "Eurobacharel" com um mínimo de 75 horas de Aulas Teóricas e 150 horas de Aulas de Laboratório.

A ECTN recomenda módulos com um mínimo de 5 créditos, i.e., o currículo de Química Analítica pode ser organizado em três módulos, o que pode facilitar a sua distribuição por mais de um semes- tre, ou atribuição de algumas tarefas a cadeiras diferentes. Cada módulo deverá ser completado com um exame. Recomenda-se, no entanto que, em vez de uma nota por cada módulo avaliado, seja atribuída uma única nota global certificando a aprendizagem em Química Analítica.

A proporção entre os tópicos do EUROCURRículo I, extraída do livro com o texto aprovado para o "FECS Curriculum" de Química Analítica [6], sofreu modificações na progressão para o EUROCURRÍCULO II, suportadas por sondagens conduzidas mais recentemente. Os "Tópicos Gerais" surgem subdivididos em "Cromatografia, Espectroscopias, Sensores"; "Estatística, Quimiometria e Garantia de Qualidade" incluem Estratégias de Amostragem, Validação de Mé- todos, Materiais de Referência, Rastreabilidade e temas afins.

\section{Referências}

1- M. Filomena G.F.C. Camōes, Boletim da Sociedade Portuguesa de Química 44/45 (1991) 37.

2- L.Niinisto e R. Kellner, Mikrochim. Acta (1991), II, 543-544

3- J.Grasselli Mikrochim. Acta (1991), II, 545-549

4- B.te Nijenhuis, Mikrochim. Acta (1991),

II, 550-554

5- R. Kellner, Mikrochim. Acta (1991), II, 555-563

6-Analytical Chemistry, ed. R. Kellner,J.-M. Mermet, M.Otto e H.M.Widmer-Wiley-VCH, Weinheim-De, 1998 